\title{
Association between Take-Out Food Consumption and Obesity among Chinese University Students: A Cross-Sectional Study
}

Yuhe Jiang ${ }^{1,+}$, Junbo Wang ${ }^{2,+}{ }^{,}$, Shaowei $\mathrm{Wu}^{3,+}{ }^{\dagger}, \mathrm{Nan} \mathrm{Li}^{4}$, Yiming Wang ${ }^{1}$, Jiarui Liu ${ }^{2}$, Xinran $\mathrm{Xu}^{1}$, Zonghan He ${ }^{1}$, Yawen Cheng ${ }^{1}$, Xueqing Zeng ${ }^{1}$, Bingwei Wang ${ }^{2}$, Chenyu Zhang ${ }^{2}$, Miao Zhao ${ }^{2}$, Zhijie Su ${ }^{2}$, Bingbing Guo ${ }^{2}$, Wenzhong Yang ${ }^{2}$ and Ruimao Zheng ${ }^{2,5,6,7, *}$

1 Department of Stomatology, Health Science Center, Peking University, Beijing 100191, China; 1510303106@pku.edu.cn (Y.J.); wang-ym@pku.edu.cn (Y.W.); 1510303126@pku.edu.cn (X.X.); 1510303103@pku.edu.cn (Z.H.); chengyawen521@126.com (Y.C.); 1510303124@pku.edu.cn (X.Z.)

2 Department of Anatomy, Histology and Embryology, Health Science Center, Peking University, Beijing 100191, China; jbwang@bjmu.edu.cn (J.W.); ljr9210909@163.com (J.L.); bwwang@bjmu.edu.cn (B.W.); zcyfighting@163.com (C.Z.); MiaoZhao@bjmu.edu.cn (M.Z.); suzhijie@bjmu.edu.cn (Z.S.); guobingb@bjmu.edu.cn (B.G.); yangwenzhong@pku.edu.cn (W.Y.)

3 Department of Occupational and Enviromental Health Science, Health Science Center, Peking University, Beijing 100191, China; shaowei_wu@bjmu.edu.cn

4 Institute of Reproductive and Child Health/Ministry of Health Key Laboratory of Reproductive Health and Department of Epidemiology and Biostatistics, School of Public Health, Peking University Health Science Center, Beijing 100191, China; linan01@pku.edu.cn

5 Key Laboratory for Neuroscience of National Health Commission, Beijing 100191, China

6 Neuroscience Research Institute, Peking University, Beijing 100191, China

7 Key Laboratory for Neuroscience of Ministry of Education, Beijing 100191, China

* Correspondence: rmzheng@pku.edu.cn; Tel.: +86-10-828-014-66

+ These authors contributed equally to this work.

\begin{abstract}
Background: The frequency of take-out food consumption has increased rapidly among Chinese college students, which has contributed to high obesity prevalence. However, the relationships between take-out food consumption, body mass index (BMI), and other individual factors influencing eating behavior among college students are still unclear. This study explored the association of take-out food consumption with gender, BMI, physical activity, preference for high-fat and high-sugar (HFHS) food, major category, and degree level among Chinese college students. Methods: Cross-sectional data were collected from 1220 college students in Beijing, China, regarding information about take-out food consumption, physical activity, and preference for HFHS food using a self-reported questionnaire. The logistic linear regression model was used to analyze the association between take-out food consumption and personal and lifestyle characteristics. Results: Out of 1220 college students, $11.6 \%$ of college students were overweight or obese. Among the personal and lifestyle characteristics, high frequency of take-out food consumption was significantly associated with a non-medical major, high preference for HFHS food, degree level, and higher BMI, but not physical activity. Conclusion: Among Chinese college students, consumption of take-out food may be affected by major category, preference for HFHS food, degree level, and BMI. This could provide guidance on restrictions of high take-out food consumption, which contributes to high obesity prevalence and high risk for metabolic diseases.
\end{abstract}

Keywords: obesity; take-out food consumption; taste preference; major category; degree level 


\section{Introduction}

Obesity, as an emergent public health issue, is a predisposing factor for many chronic diseases [1-5], such as type 2 diabetes, cardiovascular diseases, respiratory diseases [6], musculoskeletal disorders, and various types of cancer. Currently, nearly one-third of adolescents are overweight or obese in China; the obesity prevalence rate has risen from $0.10 \%$ in 1976 to $8.50 \%$ in 2016 [7], which is a relative increase by a factor of 85.0.

The obesogenic environment contributes to obesity [8]. Several lines of study have shown that fast-food consumption is closely linked to higher obesity prevalence in some Western countries [9-11] and China [12,13]. Fast food, such as hamburgers, French fries, pizza, and soda, are generally regarded as energy-dense and low-nutrient food, and tend to be rich in sugar and saturated fat. The number of restaurants of a major fast-food provider, Kentucky Fried Chicken (KFC), has increased to over 4200 in more than 800 cities and towns in China [14]. Another fast-food provider, McDonald's, has also opened over 2000 restaurants across China from 1984 to 2014 [15]. The annual sales for China's fast food industry increased from 24.2 billion in 2002 [15] to 107.0 billion United States (U.S.) dollars in 2015 [16], which is an increase of over $340 \%$.

Notably, there are approximately 587 million students in colleges and universities across the world in 2016 [17], and one-fifth of these students are Chinese. Young Chinese are facing a remarkable transformation in their diet structure, as China is under rapid economic transition. Of note, Chinese college students, as an important driving force in economic development, also face multiple stressors, such as academic pressure, employment pressure, and debt burden [18]. Furthermore, owing to the advantages of low prices, delivery efficiency, and convenience, take-out fast food is becoming popular among Chinese students. All of these factors and the obesogenic environment around universities appeared to promote energy intake and constrain energy expenditure of the students. In China, take-out food has been regarded as a major form of fast food; thus, studying the relationship between obesity frequency and take-out food consumption in Chinese universities is critical for identifying areas for the exploration. However, previous evidence regarding the associations between fast-food consumption and obesity in Chinese students, and research in this area in countries under rapid socioeconomic transitions such as China is still limited.

Fast-food consumption among students might be influenced by several individual factors, such as preference for high-fat and high-sugar (HFHS) food, degree level, medical education background, body mass index (BMI), physical activity, and gender. It has been reported that obese individuals showed significantly higher preference for take-out food [19]; thus, the palatable taste of take-out fast food possibly contributes to obesity incidence [20]. However, it is unknown whether preference for HFHS food may affect the frequency of take-out food consumption among Chinese college students. A study showed that graduate students have more sedentary time, less spare time, and less physical activity, since graduate students have heavier academic pressure than undergraduate students in China [21]. In addition to degree level, a report suggested that medical students may be considered as a subpopulation with better health consciousness than non-medical students [22], which may lead to lower consumption of take-out food among medical students. However, until recently, no study has investigated whether these factors are associated with the frequency of take-out consumption between graduate and undergraduate students, or medical and non-medical students. Besides, some reports showed that female college students may have higher health consciousness, healthier dietary habits, and may pay more attention to their BMI in comparison to male students [23-25], and male college students are more susceptible to overweight and obesity than females [26]. Nevertheless, there is little research available regarding the associations of take-out food consumption with gender among Chinese college students.

The purpose of this study was to provide a more refined understanding on take-out food consumption in Chinese college students, and assess the influences of personal and lifestyle characteristics, including preference for HFHS food, medical education background (major category), degree level, BMI status, and gender on take-out food consumption. 


\section{Materials and Methods}

\subsection{Ethics Statement}

The study was conducted between September and December in 2016 in China. Participants provided verbal informed consent, and participation was voluntary. No identifying information was collected. We tightly followed the guidance of ethics in this study to conduct analysis for research purposes, according to the guidelines laid down in the Declaration of Helsinki. All of the procedures involving human subjects were guided by the Ethics Committee of Peking University Health Science Center (PKUHSC) (LA2016113). This study met the criteria for exemption decided by the Institutional Review Board of PKUHSC. Public Health categorized this analysis as Not Human Subjects Research. Other investigators who are interested in accessing the dataset or replicating the analyses can contact the corresponding author.

\subsection{Study Groups and Design}

\subsubsection{Participants}

This study is a cross-sectional study of college students enrolled in Peking University, China. All of the participants were selected through multistage stratified random cluster sampling, and participation was voluntary. This survey was conducted in 78 classes on two campuses, and 20 students were randomly investigated in each class. Investigators distributed questionnaires to each participant, and then collected them after completion. A total of 1560 students aged 18-26 years were selected, and $78.5 \%$ of them agreed to participate, while 335 students did not finish survey questions. Participants completed the questionnaire on gender, weight, height, major, degree level, grade, habit of eating take-out food, physical activity, frequency of take-out food, and preference for HFHS food, which was all self-reported. Five individuals were excluded due to abnormal BMI (BMI $>35$ ). Therefore, the analytic sample was restricted to 1220 participants, including 528 males and 692 females.

\subsubsection{Assessment of Individuals' BMI}

The BMI (in $\mathrm{kg} / \mathrm{m}^{2}$ ) of all of the participants was calculated as weight $(\mathrm{kg})$ divided by the square of height $\left(\mathrm{m}^{2}\right)$. According to criteria developed by the Chinese Working Group on Obesity in the International Life Science Association (WGOC) [27], we divided participants into four groups: underweight $(\mathrm{BMI}<18.5)$, normal weight $(18.5 \leq \mathrm{BMI}<24)$, overweight $(24 \leq \mathrm{BMI}<28)$ and obese $(B M I \geq 28)$. We followed the WGOC standard, because Chinese people are usually at a higher risk of obesity-related diseases than Western people under the same BMI condition [28].

\subsubsection{Assessment of Take-Out Food Consumption and Preference for HFHS Food}

According to previous studies [29,30], we defined take-out food as food items from fast-food outlets with convenient delivery service, carryout food options, and payment prior to the receipt of food. We collected information about the intake frequency of each meal (breakfast, lunch, dinner, or snack) during a seven-day period before the administration of the questionnaire, food types (staple food, vegetables, or meat) and duration of eating take-out food. Take-out food included seven categories of foods: (1) grains and cereals; (2) fruits; (3) vegetables; (4) milk and milk products; (5) meat and meat products; (6) fats, oils, and sugars; (7) and beverages [31]. Regarding the assessment of habit of eating take-out food, which meant a time period of eating take-out food at least once per week, we set four choices: (1) 0-3 months; (2) 4-6 months; (3) 7-12 months; and (4) 13-24 months.

In addition, we assessed all of the participants' preference for HFHS food. A score scale of 1-4, representing no preference, little preference, moderate preference, and great preference, was used to evaluate the preference for four categories of HFHS foods: (1) meat pie, hamburger, or hot dog; (2) hot 
chips or French fries; (3) potato chips or savory snacks such as "Twisties"; and (4) biscuits, doughnuts, cake, or chocolate [32].

\subsubsection{Assessment of Physical Activity and Personal Information of the Study Participants}

According to the Simple Physical Activity Questionnaire (SIMPAQ), we investigated the information about physical activity, which included time spent in bed, sedentary time, time spent standing, time spent walking, other physical activities, and exercise during one week [33]. Notably, light physical activity was excluded in our study, such as normal walking and use of bicycle. General information was also collected on the survey, such as age, gender (male, female), height, weight, major category (medical or non-medical), and grade (undergraduate level from first year to fifth year; graduate level from first year to third year). Medical students were those majoring in Basic Medical Sciences, Clinical Medical Sciences, Nursing, Pharmaceutical Sciences, Public Health, or Dentistry [34], and all of the other students were classified as non-medical students. The degree level was classified into two categories: undergraduate level (medical students, undergraduate years $1-5$; non-medical students, undergraduate years 1-4), and graduate level (graduate years 1-3). At the end of survey, the investigator would record the corresponding class number and assign a random ordered number to the respondents from the same class.

\subsubsection{Adjustment Variables}

Analyses were adjusted for grade (undergraduate years 1-5 and graduate years 1-3). Adjustment was also made for the habit of eating take-out food to help control for potential confounding from past eating habits. Since each participant was investigated independently, the influence between classmates should be zero when completing the survey.

\subsection{Statistical Analysis}

Participants included in the data analysis have complete information on take-out food intake and personal and lifestyle characteristics, and all of the individuals were divided into three subgroups by the frequency of take-out food consumption. Then, we examined the frequency of take-out food among college student subgroups divided by gender, major category, degree level, physical activity, preference for HFHS food, and BMI status. The Chi-square test was used to test the difference among the subgroups according to categorical variables, including gender, major category, degree level, physical activity, food preference, and BMI status.

In addition, in order to examine the association between take-out food consumption and personal and lifestyle characteristics, we used logistic linear regression models to calculate the odds ratios (OR) and 95\% confidence intervals (CI). Preference for HFHS food, major category, degree level, and BMI status were included as independent variables in the regression models adjusted by gender and recent habit of eating take-out food (Model 1). On the basis of model 1, model 2 was further adjusted by physical activity to examine the association between take-out food consumption and personal and lifestyle characteristics. Since grade is highly correlated with degree level, we also conducted an analysis adjusted by gender, habit of eating take-out food, and grade (undergraduate years 1-5 and graduate years 1-3) (model 3). All of the statistical analyses were performed using IBM SPSS Statistics 24.0 (International Business Machines Corporation, Armonk, NY, USA), and statistical significance level was set at $p<0.05$ (two-sided).

\section{Results}

\subsection{Basic Anthropometric Characteristics}

Descriptive characteristics of the participants are shown in Table 1. On the whole, there were 1220 students in the study population, with ages from 18 to 26 . Among them, $56.7 \%$ were female students, $91.3 \%$ were undergraduate students, and $46.7 \%$ were medical students. In addition, $11.5 \%$ of these 
college students were overweight or obese, and the obesity prevalence was 3.5\%. For the frequency of healthy behaviors, $48.4 \%$ students had high-level physical activity ( $>12$ h per week) while 51.6\% students had low-level exercise ( $\leq 12 \mathrm{~h}$ per week).

Table 1. Basic information for the study population. BMI: body mass index.

\begin{tabular}{|c|c|c|c|c|c|c|}
\hline \multirow{2}{*}{ Variable } & \multicolumn{2}{|c|}{ Overall $(\mathrm{N}=1220)$} & \multicolumn{2}{|c|}{ Male $(\mathrm{N}=528)$} & \multicolumn{2}{|c|}{ Female $(\mathrm{N}=692)$} \\
\hline & No. & $(\%)$ & No. & $(\%)$ & No. & $(\%)$ \\
\hline \multicolumn{7}{|c|}{ Age } \\
\hline $18-23$ & 1149 & 94.2 & 485 & 91.9 & 664 & 96.0 \\
\hline$\geq 24$ & 71 & 5.8 & 43 & 9.1 & 28 & 4.0 \\
\hline \multicolumn{7}{|c|}{ Body Mass Index } \\
\hline Underweight & 214 & 17.5 & 44 & 8.3 & 170 & 24.6 \\
\hline Normal weight & 865 & 70.9 & 379 & 71.8 & 486 & 70.2 \\
\hline Overweight & 98 & 8.0 & 77 & 14.6 & 21 & 3.0 \\
\hline Obese & 43 & 3.5 & 28 & 5.3 & 15 & 2.2 \\
\hline \multicolumn{7}{|c|}{ Major } \\
\hline Medical & 570 & 46.7 & 241 & 45.6 & 329 & 47.5 \\
\hline Non-medical & 650 & 53.3 & 287 & 54.4 & 363 & 52.5 \\
\hline \multicolumn{7}{|c|}{ Educational level } \\
\hline Undergraduate & 1114 & 91.3 & 471 & 89.2 & 643 & 92.9 \\
\hline Graduate & 106 & 9.7 & 57 & 10.8 & 49 & 7.1 \\
\hline
\end{tabular}

\subsection{Assessment of the Frequency of Take-Out Food Consumption}

With regard to take-out food consumption, obese participants had higher take-out food consumption, and medical students ate take-out food less frequently than non-medical students. Additionally, graduate students were more likely to eat take-out food than undergraduate students, and individuals with a higher preference for HFHS food were more likely to eat take-out food. Notably, there was no statistically significant association between physical activity and take-out food consumption among college students (Table 2).

\subsection{Association between Take-Out Food Consumption and Personal and Lifestyle Characteristics}

For factors influencing take-out food consumption, we found that degree level was also significantly associated with take-out food consumption $(95 \% \mathrm{CI}=1.12-2.27, p$-value $=0.01)$; preference for HFHS food had a positive effect on frequency of take-out food consumption $(95 \% \mathrm{CI}=1.12-6.09$, $p$-value $<0.001)$; high BMI was associated with an OR of $1.99(95 \% \mathrm{CI}=1.26-4.68, p$-value $=0.04)$; and medical students had lower take-out food consumption than non-medical students $(95 \% \mathrm{CI}=$ 0.53-0.82, $p$-value < 0.001) (model 1, Table 3).

After further adjusting for physical activity, we obtained similar results as with model 1. Take-out food consumption was associated with a high degree level, high preference for HFHS food, high BMI, and medical background (model 2, Table 3). For model 3 (when control was made for gender, habit of eating take-out food, and grade), degree level became unassociated with frequency of take-out food consumption $(95 \% \mathrm{CI}=0.60-1.78, p$ value $=0.90)($ Table 3$)$.

\section{Discussion}

In the present study, we provided a comprehensive evaluation of the factors influencing the frequency of take-out food consumption based on data from 1220 participants at Peking University, in Beijing China. We found that obesity prevalence among college students was lower than the national average [7]; high frequency of take-out food consumption was significantly associated with non-medical major, high preference for HFHS food, graduate study, and higher BMI in both male 
and female college students in our study participants. It is noteworthy that physical activity did not significantly affect take-out food consumption among college students.

Fast-food consumption has been studied in multiple areas. Researchers have investigated the association between fast-food consumption and educational level [35], socioeconomic status [36], dietary patterns [37], hypertension [35], and obesity prevalence [38-41] among adults in the community and among students in elementary school or college. For instance, by using data collected from Euromonitor's Passport Global Market Information Database (GMID), 2012 edition, Roberto's study investigated the effect of fast-food consumption on mean population BMI, and found evidence for the association between fast-food consumption and high BMI [40]. Mark's research examining the association between reported fast-food habits and changes in body weight and insulin resistance among 3031 young adults in the United States showed that fast-food consumption has strong positive associations with weight gain and insulin resistance, which suggests that fast food increases the risk of obesity and type 2 diabetes [41]. In addition, Tambalis's study used data from 177,091 Greek children and adolescents, and found that frequent fast-food consumption was associated with skipping breakfast and consuming sweets/candy, based on the EYZHN (National Action for Children's Health) program [42]. On the basis of these results, many researchers have recommended further interventions to help children adopt healthier dietary habits.

A recent research study also examined the association between fast-food consumption and education level among 478 working adults in the United States [43]. The study used cross-sectional survey data collected from full-time and part-time employees of a large university located in the southeastern United States, and found that low educational attainment was related to a greater fast-food intake among women and men. For example, fast-food consumption was greatest in participants with no college education, and lowest in those with a graduate or professional degree. Specifically, males reported a greater fast-food consumption compared with females [43]. More recently, an elegantly designed cross-sectional study also found strong evidence for the influence of new media exposure to fast-food consumption among Chinese children and adolescents aged between six and 18 [44]. The study showed that watching online videos and playing computer games are behaviors associated with higher probabilities of eating at fast food restaurants in both rural and urban young residents, suggesting that new media exposure has an enormous effect on fast-food consumption in China [44]. In conclusion, previous work showed evidence for the influence of personal and lifestyle characteristics on fast-food consumption. 
Table 2. Number of individuals across personal and lifestyle characteristics as well as categories of take-out food consumption. HFHS: high fat and high sugar.

\begin{tabular}{|c|c|c|c|c|c|c|c|c|c|}
\hline \multirow{3}{*}{ Characteristics } & \multicolumn{8}{|c|}{ Take-Out Food Consumption } & \multirow{3}{*}{$p$} \\
\hline & \multicolumn{2}{|c|}{ Overall } & \multicolumn{2}{|c|}{ Tertile 1 (4-5 times/week) } & \multicolumn{2}{|c|}{ Tertile 2 (6-8 times/week) } & \multicolumn{2}{|c|}{ Tertile 3 (9-15 times/week) } & \\
\hline & No. & $(\%)$ & No. & $(\%)$ & No. & $(\%)$ & No. & $(\%)$ & \\
\hline Total & 1220 & 100 & 443 & 36.3 & 428 & 35.1 & 349 & 28.6 & \\
\hline \multicolumn{10}{|l|}{ Gender } \\
\hline Men & 529 & 43.4 & 174 & 14.3 & 191 & 15.7 & 164 & 13.4 & \multirow[b]{2}{*}{$0.08^{*}$} \\
\hline Women & 691 & 56.6 & 269 & 22.0 & 237 & 19.4 & 185 & 15.2 & \\
\hline \multicolumn{10}{|l|}{ Major } \\
\hline Non-medical students & 650 & 53.3 & 211 & 17.3 & 222 & 18.2 & 217 & 17.8 & \multirow[b]{2}{*}{$<0.001^{* * *}$} \\
\hline Medical students & 570 & 46.7 & 232 & 19.0 & 206 & 16.9 & 132 & 10.8 & \\
\hline \multicolumn{10}{|l|}{ Degree level } \\
\hline Undergraduate & 1114 & 91.3 & 422 & 34.6 & 383 & 31.4 & 309 & 25.3 & \multirow{2}{*}{$0.001 * *$} \\
\hline Graduate & 106 & 8.7 & 21 & 1.7 & 45 & 3.7 & 40 & 3.3 & \\
\hline \multicolumn{10}{|l|}{ Physical activity } \\
\hline Low ( $\leqq 12 \mathrm{~h} /$ week) & 629 & 51.6 & 233 & 19.1 & 215 & 17.6 & 181 & 14.8 & \multirow[b]{2}{*}{0.78} \\
\hline $\operatorname{High}(>12 \mathrm{~h} /$ week $)$ & 591 & 48.4 & 210 & 17.2 & 213 & 17.5 & 168 & 13.8 & \\
\hline \multicolumn{10}{|l|}{ Preference for HFHS food } \\
\hline Low $(2-6)$ & 441 & 36.1 & 188 & 15.4 & 155 & 12.7 & 98 & 8.0 & \multirow{3}{*}{$<0.001^{* * *}$} \\
\hline Moderate (7-9) & 388 & 31.9 & 142 & 11.6 & 143 & 11.7 & 103 & 8.4 & \\
\hline High (10-16) & 391 & 32.0 & 113 & 9.3 & 130 & 10.7 & 148 & 12.1 & \\
\hline \multicolumn{10}{|l|}{ BMI } \\
\hline Underweight & 214 & 17.5 & 71 & 5.8 & 71 & 5.8 & 72 & 2.9 & \multirow{4}{*}{0.02} \\
\hline Normal weight & 865 & 70.9 & 296 & 24.3 & 291 & 23.9 & 278 & 22.7 & \\
\hline Overweight & 98 & 8.1 & 31 & 2.5 & 32 & 2.6 & 35 & 2.9 & \\
\hline Obese & 43 & 3.5 & 7 & 0.6 & 10 & 0.8 & 26 & 2.1 & \\
\hline
\end{tabular}


Table 3. Odds ratios (ORs) of take-out food consumption associated with personal and lifestyle characteristics.

\begin{tabular}{|c|c|c|c|c|c|c|}
\hline \multirow{2}{*}{ Characteristic } & \multicolumn{2}{|c|}{ Model $1^{1}$} & \multicolumn{2}{|c|}{ Model $2^{2}$} & \multicolumn{2}{|c|}{ Model $3^{3}$} \\
\hline & OR $(95 \%$ CI) & $p$-Value ${ }^{3}$ & OR (95\% CI) & $p$-Value & OR (95\% CI) & $p$-Value \\
\hline \multicolumn{7}{|l|}{ Preference for HFHS food } \\
\hline Low $(2-6)$ & 1.00 & - & 1.00 & - & 1.00 & - \\
\hline Moderate (7-9) & $1.39(1.14-3.05)$ & $0.001^{* *}$ & $1.56(1.20-2.04)$ & $0.001^{* *}$ & $1.58(1.22-2.04)$ & $<0.001^{* * *}$ \\
\hline High (10-16) & $2.61(1.12-6.09)$ & $<0.001^{* * *}$ & $2.08(1.58-2.70)$ & $<0.001^{* * *}$ & $2.27(1.61-2.78)$ & $<0.001^{* * *}$ \\
\hline \multicolumn{7}{|l|}{ Major } \\
\hline Non-medical students & 1.00 & - & 1.00 & - & 1.00 & - \\
\hline Medical students & $0.66(0.53-0.82)$ & $<0.001^{* * *}$ & $0.66(0.57-0.81)$ & $<0.001^{* * *}$ & $0.67(0.53-0.81)$ & $<0.001^{* * *}$ \\
\hline \multicolumn{7}{|l|}{ Degree level } \\
\hline Undergraduate & 1.00 & - & 1.00 & - & 1.00 & - \\
\hline Graduate & $1.61(1.12-2.27)$ & $0.01 *$ & $2.19(1.39-3.43)$ & $0.009 * *$ & $1.03(0.60-1.78)$ & 0.90 \\
\hline \multicolumn{7}{|l|}{ BMI } \\
\hline Underweight & 1.00 & - & 1.00 & - & 1.00 & - \\
\hline Normal weight & $1.41(0.84-3.21)$ & 0.15 & $1.19(0.54-2.62)$ & 0.67 & $1.67(0.84-3.33)$ & 0.17 \\
\hline Overweight & $1.62(0.89-2.91)$ & 0.09 & $1.69(0.84-3.03)$ & 0.16 & $1.69(0.94-3.13)$ & 0.06 \\
\hline Obese & $1.99(1.26-4.68)$ & $0.04 *$ & $2.02(1.78-5.46)$ & $0.02 *$ & $2.26(1.98-5.83)$ & $0.01 *$ \\
\hline
\end{tabular}


In our study, we also found some factors influencing take-out food consumption. Our contribution to the literature is that the frequency of take-out food consumption was significantly associated with major category, preference for HFHS food, degree level, and BMI among Chinese college students. College life is an important period for personal health. Compared to students from primary school or high school settings, college students have better economic conditions and can decide where to eat by themselves. They not only have meals in the school cafeteria, but also consume take-out food through an electronic trading platform, which provides a convenient delivery service. Since students in Peking University only have short winter and summer holidays (one month and two months, respectively), they are exposed to an obesogenic environment most of the time, such as MacDonald's, KFC, and other fast-food restaurants around the university. In our study, students' major category seems to be associated with their take-out food consumption. One potential explanation is that comparing to non-medical students, medical students are equipped with more professional medical knowledge and better health awareness, which are critical for avoiding consuming take-out food [22].

With regard to physical activity, vigorous-intensity exercise significantly promotes the development of good health consciousness in students, which is a potential factor for reducing take-out food consumption [45]. Surprisingly, based on our study, physical activity did not show a significant influence on take-out food consumption; this may have been attributed to the higher frequency of eating in the school cafeteria. Being characterized with cheap food and short waiting time, students prefer to have meals in school cafeteria rather than eating take-out food after vigorous-intensity exercise and low-intensity exercise. As the association between take-out food consumption and physical activity is still elusive, further research is needed to determine whether take-out food consumption is related to physical activity behaviors.

Another interesting finding in our study is that degree level was associated with take-out food consumption among Chinese college students. The odds of graduate students' consumption of take-out food increased 1.19 times compared to undergraduate students. Graduate students tend to have higher academic pressure and less spare time; thus, they are more likely to consume take-out food due to the time saved. In this study, our analysis demonstrates that a high frequency of take-out food consumption was associated with a higher degree level among college students. Notably, there has been research showing that compared to those with high education levels, adults with low education levels have worse health consciousness [46], which may promote them to eat more low-quality food with high amounts of fat, cholesterol, saturated fatty acids, sugar, alcohol, and sodium. It suggests that working pressure and health consciousness may play important roles in influencing take-out food consumption. Therefore, our finding further suggests that an education-based strategy on the enhancement of health consciousness may serve as an intervention mean to restrict take-out food consumption. Importantly, reducing the number of take-out food restaurants around university may also contribute to the restriction on fast-food consumption.

There are several strengths in our study. To the best of our knowledge, this study is the first university-level study to investigate the associations between take-out food consumption and personal and lifestyle characteristics, including gender, preference for HFHS food, degree level, major category, and BMI status. Compared to Westerners, the risk of obesity-related diseases is usually higher among Chinese under the same BMI condition. Therefore, we categorized BMI according to the WGOC recommendation criteria. We also utilized a randomization design to support the validity of our results. Additionally, adjustment for individual histories of eating take-out food helps control the potential confounding from past eating habits.

Our study also has several limitations. The major limitations are the representativeness of our sample and the generalizability of our findings. Our data are not representative of the national college student population, and thus its generalizability may be limited. Given the geographical heterogeneity in economic development and nutritional environments, examining regional variations in take-out food consumption and its associations with health-related factors (e.g., BMI, physical activity, and preference of HFHS food) and demographic factors (e.g., gender, major category, and educational level) 
are encouraged in future research. Second, all of the data were self-reported by students, and therefore may be subject to potential recall bias. Third, our study lacks a measure of individual economic condition, which was presumably highly correlated with the frequency of take-out food consumption. Finally, the cross-sectional nature of our data does not support causal inferences between take-out food consumption and personal and lifestyle characteristics, which limits our study's ability to guide practical interventions.

\section{Conclusions}

Our findings support that a high frequency of take-out food consumption was significantly associated with high preference for HFHS food, degree level, non-medical major, and high BMI. Based on our findings, we suggest that health-promoting activities should be directed to the students with unhealthy lifestyles, and should be particularly focused on decreasing the consumption of take-out food as well as improving medical knowledge [35]. Considering that take-out food consumption could be linked to adverse health outcomes through plausible mechanisms, further research is necessary to investigate the unhealthy consequences of rapidly increasing take-out food consumption, especially in the countries experiencing rapid economic growth. Most importantly, although the causes of obesity are multifaceted, public health measures to limit take-out food consumption in college students may be warranted. Such measures could include nutrition education campaigns, legislation to regulate the marketing of take-out food, and the elimination of take-out food from schools.

Author Contributions: Conceptualization, Y.J., J.W. and R.Z.; Data curation, Y.J., Y.W., X.X., Z.H., Y.C. and X.Z.; Formal analysis, Y.J., J.W., S.W., N.L., J.L. and R.Z.; Funding acquisition, Y.J. and R.Z.; Investigation, Y.J., J.W., Y.W., X.X., Z.H., Y.C. and X.Z.; Methodology, J.W., S.W. and R.Z.; Project administration, R.Z.; Software, J.W.; Supervision, R.Z.; Writing - original draft, Y.J., J.W., S.W., N.L., J.L., B.W., C.Z., M.Z., Z.S., B.G., W.Y. and R.Z.; Writing - review and editing, J.W., S.W. and R.Z.

Funding: This research was funded by the National Natural Science Foundation of China (No. 81471064, No. 81670779 and No. 81870590), the Beijing Municipal Natural Science Foundation (No. 7162097 and No. H2018206641), the Peking University Research Foundation (No. BMU20140366), and the National Key Research and Development Program of China (2017YFC1700402). Y.J. received funding from Student Innovation Training Program of Peking University Health Science Center for this study.

Acknowledgments: In this research, we thank Simin Yang and Jun Lv for designing help.

Conflicts of Interest: The authors declare no conflict of interest.

\section{References}

1. Wang, Y.; Wang, L.; Qu, W. New national data show alarming increase in obesity and noncommunicable chronic diseases in China. Eur. J. Clin. Nutr. 2017, 71, 149-150. [CrossRef]

2. Wouters, E.F.M. Obesity and metabolic abnormalities in chronic obstructive pulmonary disease. Ann. Am. Thorac. Soc. 2017, 14 (Suppl. 5), S389-S394. [CrossRef]

3. Rao, H.; Wu, E.; Fu, S.; Yang, M.; Feng, B.; Lin, A.; Fei, R.; Fontana, R.J.; Lok, A.S.; Wei, L. The higher frequency of truncal obesity and diabetes in American than Chinese patients with chronic hepatitis $\mathrm{C}$ might contribute to more rapid progression to advanced liver disease. Aliment. Pharmacol. Ther. 2017, 46, 731-740. [CrossRef] [PubMed]

4. Mahmoodnia, L. and Tamadon, M.R. On the occasion of world kidney day 2017; obesity and its relationship with chronic kidney disease. J. Nephropathol. 2017, 6, 105-109. [CrossRef]

5. Lai, S.H.; Tsai, Y.W.; Chen, Y.C.; Chang, S.S. Obesity, hyperhomocysteinaemia and risk of chronic kidney disease: A population-based study. Fam. Pract. 2017. [CrossRef] [PubMed]

6. Goto, T.; Hirayama, A.; Faridi, M.K.; Camargo, C.A., Jr.; Hasegawa, K. Obesity and severity of acute exacerbation of chronic obstructive pulmonary disease. Ann. Am. Thorac. Soc. 2018, 15, 184-191. [CrossRef] [PubMed]

7. Global Health Observatory Data Repository. 2017. Available online: http://apps.who.int/gho/data/view. main.BMIPLUS2C10-19v?lang=en (accessed on 29 September 2017). 
8. Williams, J.; Scarborough, P.; Townsend, N.; Matthews, A.; Burgoine, T.; Mumtaz, L.; Rayner, M. Associations between food outlets around schools and BMI among primary students in England: A cross-classified multi-level analysis. PLoS ONE 2015, 10, e0132930. [CrossRef] [PubMed]

9. Virtanen, M.; Kivimäki, H.; Ervasti, J.; Oksanen, T.; Pentti, J.; Kouvonen, A.; Halonen, J.I.; Kivimäki, M.; Vahtera, J. Fast-food outlets and grocery stores near school and adolescents' eating habits and overweight in Finland. Eur. J. Public Health 2015, 25, 650-655. [CrossRef] [PubMed]

10. Anderson, B.; Rafferty, A.P.; Lyon-Callo, S.; Fussman, C.; Imes, G. Fast-food consumption and obesity among michigan adults. Prev. Chronic Dis. 2011, 8, A71.

11. Fraser, L.K.; Clarke, G.P.; Cade, J.E.; Edwards, K.L. Fast food and obesity: A spatial analysis in a large United Kingdom population of children aged 13-15. Am. J. Prev. Med. 2012, 42, e77-e85. [CrossRef]

12. Ko, G.T.; Chan, J.C.; Tong, S.D.; Chan, A.W.; Wong, P.T.; Hui, S.S.; Kwok, R.; Chan, C.L. Associations between dietary habits and risk factors for cardiovascular diseases in a Hong Kong Chinese working population-The "Better Health for Better Hong Kong" (BHBHK) health promotion campaign. Asia Pac. J. Clin. Nutr. 2007, 16, 757-765. [PubMed]

13. Shan, X.Y.; Xi, B.; Cheng, H.; Hou, D.Q.; Wang, Y.; Mi, J. Frequency and behavioral risk factors of overweight and obesity among children aged 2-18 in Beijing, China. Int. J. Pediatr. Obes. 2010, 5, 383-389. [CrossRef] [PubMed]

14. Wang, Y.; Wang, L.; Xue, H.; Qu, W. A review of the growth of the fast food industry in China and its potential impact on obesity. Int. J. Environ. Res. Public Health 2016, 13. [CrossRef]

15. Xue, H.; Wu, Y.; Wang, X.; Wang, Y. Time trends in fast food consumption and its association with obesity among children in China. PLoS ONE 2016, 11, e0151141. [CrossRef]

16. Data for the Chinese Industry Information. 2016. Available online: http://www.chyxx.com/industry/ 201609/452792.html (accessed on 28 September 2016).

17. Data for the Sustainable Development Goals. 2018. Available online: http://data.uis.unesco.org/ (accessed on 8 April 2018).

18. Hurst, C.S.; Baranik, L.E.; Daniel, F. College student stressors: A review of the qualitative research. Stress Health 2013, 29, 275-285. [CrossRef]

19. Proserpio, C.; Laureati, M.; Bertoli, S.; Battezzati, A.; Pagliarini, E. Determinants of obesity in Italian adults: The role of taste sensitivity, food liking, and food neophobia. Chem. Senses 2016, 41, 169-176. [CrossRef]

20. Salbe, A.D.; DelParigi, A.; Pratley, R.E.; Drewnowski, A.; Tataranni, P.A. Taste preferences and body weight changes in an obesity-prone population. Am. J. Clin. Nutr. 2004, 79, 372-378. [CrossRef] [PubMed]

21. Zhang, R.; Yin, M.; Wu, X. The comparative research and thought between postgraduate students and regular course students on their health consciousness, physical quality and practice. J. Nanjing Inst. Phys. Educ. 2005, 19,84-87.

22. Mehmood, Y.; Al-Swailmi, F.K.; Al-Enazi, S.A. Frequency of obesity and comorbidities in medical students. Pak. J. Med. Sci. 2016, 32, 1528-1532. [CrossRef]

23. Tanenbaum, H.C.; Felicitas, J.Q.; Li, Y.; Tobias, M.; Chou, C.P.; Palmer, P.H.; Spruijt-Metz, D.; Reynolds, K.D.; Anderson Johnson, C.; Xie, B. Overweight perception: Associations with weight control goals, attempts, and practices among Chinese female college students. J. Acad. Nutr. Diet. 2016, 116, 458-466. [CrossRef]

24. Lee, S.; Leung, T.; Lee, A.M.; Yu, H.; Leung, C.M. Body dissatisfaction among Chinese undergraduates and its implications for eating disorders in Hong Kong. Int. J. Eat. Disord. 1996, 20, 77-84. [CrossRef]

25. Sakamaki, R.; Toyama, K.; Amamoto, R.; Liu, C.J.; Shinfuku, N. Nutritional knowledge, food habits and health attitude of Chinese university students-A cross sectional study. Nutr. J. 2005, 4. [CrossRef] [PubMed]

26. Gretebeck, K.A.; Sabatini, L.M.; Black, D.R.; Gretebeckl, R.J. Physical activity, functional ability, and obesity in older adults: A gender difference. J. Gerontol. Nurs. 2017, 43, 38-46. [CrossRef] [PubMed]

27. Ji, C.; WGOC. The prevalence of childhood overweight/obesity and the epidemic changes in 1985-2000 for Chinese school-age children and adolescents. Obes. Rev. 2008, 9 (Suppl. 1), 78-81. [CrossRef]

28. Wang, Y.; Mi, J.; Shan, X.Y.; Wang, Q.J.; Ge, K.Y. Is China facing an obesity epidemic and the consequences? The trends in obesity and chronic disease in China. Int. J. Obes. (Lond.) 2007, 31, 177-188. [CrossRef]

29. Burgoine, T.; Forouhi, N.G.; Griffin, S.J.; Brage, S.; Wareham, N.J.; Monsivais, P. Does neighborhood fast-food outlet exposure amplify inequalities in diet and obesity? A cross-sectional study. Am. J. Clin. Nutr. 2016, 103, 1540-1547. [CrossRef] 
30. Miura, K.; Giskes, K.; Turrell, G. Socio-economic differences in takeaway food consumption among adults. Public Health Nutr. 2012, 15, 218-226. [CrossRef] [PubMed]

31. Paeratakul, S.; Ferdinand, D.P.; Champagne, C.M.; Ryan, D.H.; Bray, G.A. Fast-food consumption among U.S. adults and children: Dietary and nutrient intake profile. J. Am. Diet. Assoc. 2003, 103, 1332-1338. [CrossRef]

32. Millar, L.; Rowland, M.; Nichols, B.; Swinburn, C.; Bennett, H.; Skouteris, H.; Allender, S. Relationship between raised BMI and sugar sweetened beverage and high fat food consumption among children. Obesity 2014, 22, E96-E103. [CrossRef]

33. Schilling, R.; Scharli, E.; Fischer, X.; Donath, L.; Faude, O.; Brand, S.; Puhse, U.; Zahner, L.; Rosenbaum, S.; Ward, P.B. The utility of two interview-based physical activity questionnaires in healthy young adults: Comparison with accelerometer data. PLOS ONE 2018, 13, e0203525. [CrossRef]

34. Yuan, C.; Lv, J.; VanderWeele, T.J. An assessment of health behavior peer effects in Peking University dormitories: A randomized cluster-assignment design for interference. PLoS ONE 2013, 9, e75009. [CrossRef] [PubMed]

35. Zhao, Y.; Wang, L.; Xue, H.; Wang, H.; Wang, Y. Fast food consumption and its associations with obesity and hypertension among children: Results from the baseline data of the Childhood Obesity Study in China Mega-cities. BMC Public Health 2017, 17, 933. [CrossRef] [PubMed]

36. Black, J.L.; Billette, J.M. Fast food intake in Canada: Differences among Canadians with diverse demographic, socio-economic and lifestyle characteristics. Can. J. Public Health 2015, 106, e52-e58. [CrossRef]

37. Poti, J.M.; Duffey, K.J.; Popkin, B.M. The association of fast food consumption with poor dietary outcomes and obesity among children: Is it the fast food or the remainder of the diet? Am. J. Clin. Nutr. 2014, 99, 162-171. [CrossRef]

38. Pisarik, P. Compensation for energy intake from fast food among overweight and lean adolescents. JAMA 2004, 292, 1304. [CrossRef]

39. Mohammadbeigi, A.; Asgarian, A.; Moshir, E.; Heidari, H.; Afrashteh, S.; Khazaei, S.; Ansari, H. Fast food consumption and overweight/obesity prevalence in students and its association with general and abdominal obesity. J. Prev. Med. Hyg. 2018, 59, E236-E240. [CrossRef] [PubMed]

40. De Vogli, R.; Kouvonen, A.; Gimeno, D. The influence of market deregulation on fast food consumption and body mass index: A cross-national time series analysis. Bull. World Health Organ. 2014, 92, 99-107. [CrossRef] [PubMed]

41. Pereira, M.A.; Kartashov, A.I.; Ebbeling, C.B.; Van Horn, L.; Slattery, M.L.; Jacobs, D.R.; Jr Ludwig, D.S. Fast-food habits, weight gain, and insulin resistance (the CARDIA study): 15-year prospective analysis. Lancet 2005, 365, 36-42. [CrossRef]

42. Tambalis, K.D.; Panagiotakos, D.B.; Psarra, G.; Sidossis, L.S. Association between fast-food consumption and lifestyle characteristics in Greek children and adolescents; results from the EYZHN (National Action for Children's Health) programme. Public Health Nutr. 2018, 21, 3386-3394. [CrossRef] [PubMed]

43. Garza, K.B.; Ding, M.; Owensby, J.K.; Zizza, C.A. Impulsivity and fast-food consumption: A cross-sectional study among working adults. J. Acad. Nutr. Diet. 2015, 116, 61-68. [CrossRef] [PubMed]

44. Hansstein, F.V.; Hong, Y.; Di, C. The relationship between new media exposure and fast food consumption among Chinese children and adolescents in school: A rural-urban comparison. Glob. Health Promot. 2017, 24, 40-48. [CrossRef] [PubMed]

45. Watts, A.W.; Rydell, S.A.; Eisenberg, M.E.; Laska, M.N.; Neumark-Sztainer, D. Yoga's potential for promoting healthy eating and physical activity behaviors among young adults: A mixed-methods study. Int. J. Behav. Nutr. Phys. Act. 2018, 15, 42. [CrossRef] [PubMed]

46. Landstrom, E.; Hursti, U.K.; Becker, W.; Magnusson, M. Use of functional foods among Swedish consumers is related to health-consciousness and perceived effect. Br. J. Nutr. 2007, 98, 1058-1069. [CrossRef] [PubMed]

(C) 2019 by the authors. Licensee MDPI, Basel, Switzerland. This article is an open access article distributed under the terms and conditions of the Creative Commons Attribution (CC BY) license (http://creativecommons.org/licenses/by/4.0/). 